\title{
Effects of a screening tool and conferences on nurses' discharge-planning ability in a hospital without a discharge-planning department
}

\author{
Tsukasa Domoto $^{1}$, Yukie Takemura², Satoko Nagata ${ }^{3}$ \\ 1. Japanese Red Cross Hiroshima College of Nursing, Japan. 2. Research Hospital, The Institute of Medical Science, The \\ University of Tokyo, Japan. 3. The University of Tokyo, Japan.
}

Correspondence: Tsukasa Domoto. Address: Japanese Red Cross Hiroshima College of Nursing, Japan.

Email: tsukasadomoto@gmail.com

Received: September 11, 2013 Accepted: June 16, 2014

Online Published: June 26, 2014

DOI : $10.5430 /$ cns.v2n3p127

URL: http://dx.doi.org/10.5430/cns.v2n3p127

\begin{abstract}
Aim: To evaluate the effects of adopting a screening tool and conferences for discharge planning on staff nurses' practical ability to perform discharge planning procedures for high-risk patients requiring special discharge plans, in a hospital without a discharge-planning department.

Methods: A quasi-experimental single-group pretest-posttest design was used. Participants were 48 staff nurses and 68 patients in a 135-bed hospital in the Tokyo area. The intervention included the adoption of the Screening Tool for Discharge Planning and discharge-planning conferences in daily nursing practices. Staff nurses answered a self-administered questionnaire about their discharge planning before and after the intervention period and evaluated inpatient needs for discharge planning during the investigation period.
\end{abstract}

Results: Pre- and post-intervention self-evaluations of discharge-planning ability were obtained from 36 nurses. Scores on the screening and monitoring subscales and the sum total of the Discharge Planning-Process Evaluation Measurement significantly improved after the intervention. In addition, staff nurses could more accurately identify high-risk patients after the intervention, but the increase was not significant.

Conclusion: The intervention was successful in improving staff nurses' discharge-planning abilities and possibly even the identification of high-risk patients, suggesting that the intervention may be effective in hospitals without discharge-planning departments.

\section{Key words}

Conference, Discharge planning, Nursing, Quasi-experimental design, Screening tool

\section{I ntroduction}

In recent years, substantial increases in care needs and medical expenses have become an issue of concern in Japan as the population ages. Hospital stays are being shortened and the immediate shift to a lower-level care facility is promoted in acute hospitals. Under such circumstances, identifying patients in need of discharge planning and conducting discharge management immediately after admission is important ${ }^{[1]}$. 
The identification of such patients and planning for discharge within seven days of admission have been added to the revised medical treatment fee schedule ${ }^{[2]}$. Since the introduction of a of discharge planning department is a requirement for the reimbursement of discharge planning fees ${ }^{[3]}$, the number of hospitals in Japan with a discharge-planning department is rising ${ }^{[4]}$. Discharge-planning department staff usually comprises nurses and social workers; care coordination and social work are the main roles performed by this department in Japan. Previous studies have indicated that hospitals with a discharge-planning department demonstrated increased recognition and implementation of discharge planning by ward nurses, and more positive attitudes towards discharge planning compared to hospitals without a discharge-planning department ${ }^{[5,6]}$. However, in Japan, $63.5 \%$ of hospitals with over 200 beds have discharge-planning departments whereas only $36.5 \%$ of hospitals with $100-199$ beds do ${ }^{[4]}$. In large-scale hospitals, the rate for specialist placements for discharge planning was high ${ }^{[7]}$. However, it is substantially more difficult for small- and medium-sized hospitals to establish standalone departments, requiring staff nurses to play important roles in discharge planning.

Problems related to discharge planning by staff nurses include difficulty of discharge assessment due to the lack of images of the lives of patients who used local resources post-discharge ${ }^{[8]}$, and the lack of knowledge about services such as home nursing care ${ }^{[9,10]}$. Furthermore, discharge planning, involving a considerable amount of time, may be left uncompleted by staff nurses ${ }^{[11]}$. In addition, communication among staff nurses is fundamental in ensuring a successful discharge planning process ${ }^{[12,13]}$; nonetheless, communication may break down during shift changes ${ }^{[14]}$ because shift workers tend to focus on short-term treatment goals and may not be fully aware of the discharge planning process. Sharing information among staff nurses about the patient could facilitate the discharge process.

In hospitals without a discharge-planning department, it is necessary to develop countermeasures to deal with these problems. Staff nurses must first make accurate judgments in identifying patients in need of discharge planning, and predict post-discharge problems and prognosis; thus assessments of post-discharge support is required.

Screening tools have been developed to identify patients in need of discharge planning ${ }^{[15-17]}$ and allow for more consistent assessments across staff nurses. Some tools provide a numeric score that identify patients who require discharge planning ${ }^{[18-20]}$. Intervention programs that include the adoption of a screening tool in hospitals with a discharge-planning department, were found to improve staff nurses' understanding about discharge planning ${ }^{[21]}$, increase patients' satisfaction with the transition to post-discharge life ${ }^{[22]}$, and decrease the length of hospital stays ${ }^{[23]}$.

The implementation of conferences wherein ward nurses discuss and share information about patient care pertaining to discharge may be effective. Generally, nursing conferences for ward nurses aid cooperative learning ${ }^{[24]}$ by increasing individual motivation to learn through mutual encouragement ${ }^{[25,26]}$. A previous study assessing the effectiveness of a periodic conference found that self-evaluations of staff nurses' practical ability significantly improved in the intervention group $^{[27]}$. Thus, conferences could potentially contribute to the acquisition of knowledge about patient and family needs, and the improvement of practical abilities to perform discharge-planning procedures such as identifying high-risk patients requiring specialized discharge plans, assessing the patients' and families' needs, and implementing plans to meet these needs, while constantly keeping the discharge plan in mind.

Intervention studies about discharge planning generally compare the typical support provided by ward staff with support provided by trained discharge-planning nurses ${ }^{[28,29]}$. However, no intervention study has previously evaluated the staff nurses' impact on discharge planning at a hospital without a discharge-planning department. This is the first intervention study to evaluate staff nurses' impact on discharge planning at a hospital without a discharge-planning department. Based on care management process that Shirasawa described ${ }^{[30]}$, we planned intervention contents to collect patient information, extract patient needs, optimally direct support, and utilize social resources. A screening tool was used to collect information whereas the remaining processes were conducted by implementing conferences. 
The objectives of this study are to examine the impact of adopting a screening tool and conferences for discharge planning in daily nursing practices, particularly in a hospital without a discharge-planning department. The hypotheses are as follows:

Hypothesis 1: Staff nurses will rate their practical ability in discharge planning more positively after the intervention than before the intervention.

Hypothesis 2: Staff nurses will be able to better identify patients needing discharge planning after the intervention than before the intervention.

\section{Method}

\subsection{Study design}

This study used a quasi-experimental single-group pretest-posttest design (see Figure 1).

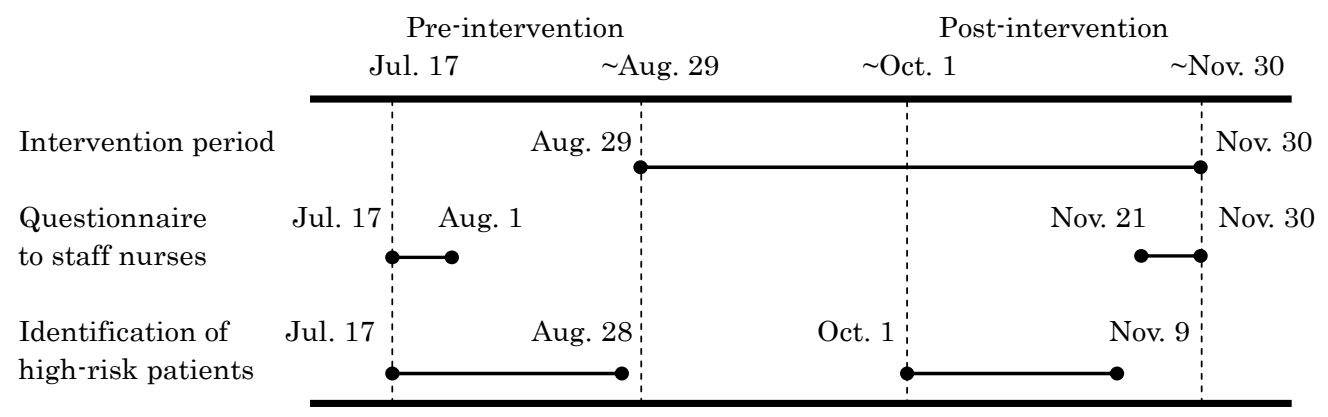

Figure 1. Intervention period and duration of the measurement of study outcomes

Staff nurses completed a questionnaire survey prior to, and at the end of the intervention period. Investigation of post-intervention changes was planned at the end of the intervention period, after exposure to adequate interventions.

Identification of high-risk patients was conducted before and at the end of the intervention period. The intervention was presented from August 29 to November 30, 2012. We expected no immediate intervention effect. Therefore, beginning one month after the intervention's commencement, we conducted the survey assessing staff nurses' judgment in identify high-risk patients. Since the identification of high-risk patients utilized the screening tool, it was administered during the intervention period, that is, we performed it concurrently with intervention.

\subsection{Participants}

\subsubsection{Features of the hospital}

The hospital, located in a metropolitan area of Tokyo, had 135 beds. In 2012, the mean hospital stay was 14.5 days. There was no discharge-planning department, and a social worker performed consultations mainly about patients' medical and living expenses, and use of the social security system. Discharge planning was conducted according to each staff nurse's judgment, and discharge conferences were not carried out. The study was conducted only in one surgery ward and two medicine wards from a total of four wards (one surgery ward, two medicine wards, and one transplant ward) in this hospital. The transplant ward was excluded due to restricted contact with inpatients because of their vulnerability to infection. 


\subsubsection{Staff nurses}

Possible study participants were 48 staff nurses (including ward chief nurses) working at the three previously described wards.

\subsubsection{Patients}

Adult patients who had been inpatients for more than five days were considered for study participation; permission of a physician and the chief nurse of the patient's ward were required for inclusion. Patients undergoing chemotherapy are often periodically repeating a four-day admission; therefore, we excluded patients with short-term hospitalizations.

\subsection{I ntervention program}

\subsubsection{Adoption of the screening tool for discharge planning in daily nursing practices}

The Screening Tool for Discharge Planning (STDP) was used, the validity and reliability of which have previously been established ${ }^{[20]}$. The STDP is a questionnaire that staff nurses fill in just after patient admission. Seven items gather information about the patient's age, degree of assistance required for activities of daily living (ADL), diagnosis of dementia or impairment of memory or understanding, family care system (whether the patient resides with the primary caregiver, the caregiver's employment and health status, and whether the caregiver was anxious about caring for the patient, or had no additional support at home), necessity of Long-Term Care Insurance (LTCI), medical measures and care required after discharge, and patient or family's desire to transfer to another hospital or institution after discharge. Weighted point scoring was utilized for each item and total scores ranged from 0 to 33 points. Patients scoring 10 or more points were considered high-risk patients.

\subsubsection{Adoption of conferences for high-risk patients' discharge planning in daily nursing practices}

A conference sheet was developed by the researchers using the items of the STDP and Rorden and Taft's ${ }^{[31]}$ indicators of health balance. The conference sheet contained information about the patient's condition and ability for self-care, family care system, post-discharge medical measures, care requirements, and need for social services. In the conference for discharge planning, staff nurses discussed patient information, assessment for discharge, and the expected extent of discharge-related support based on the conference sheet. A researcher who was a specialized nurse experienced in discharge planning at another hospital participated in conferences and advised staff nurses.

The method and frequency of the conference was decided with the chief nurse based on the typical conference conducted for each ward. Two wards implemented regular weekly conferences for high-risk patients. In one ward, evaluations of all inpatients were conducted every day, so the researcher participated only in evaluations of high-risk patients.

Before implementing the intervention, the researchers delivered a training session for all staff nurses as part of a continuing education class, to provide instructions for the completion of the STDP and conference sheets. During the session, the researchers explained the discharge planning process and provided the basic knowledge about LTCI that was necessary for STDP completion, and the staff nurses practiced completing the STDP using examples of typical patients.

\subsection{Data collection}

\subsubsection{Questionnaire survey of staff nurses}

All staff nurses were asked to complete a self-administered questionnaire before and at the end of the intervention. A researcher distributed explanation documents and questionnaires to chief nurses and asked for them to be distributed to staff nurses. Questionnaires were returned to the researchers in sealed envelopes. To allow for measurement of pre- and post-intervention changes for individual nurses, staff identification numbers were marked on the questionnaires. 
For evaluation of practical ability in discharge planning, the Discharge Planning-Process Evaluation Measurement (DCP-PEM; reliability and validity previously established) ${ }^{[32]}$ was used. The DCP-PEM includes 26 subjective questions in five areas for individual reporting: screening, assessment, care planning, implementation and monitoring. Answers ranged from 1 (very poor) to 5 (very good), with the total score ranging from 26 to 130 . Higher scores indicate superior practical ability in discharge planning. Considering the target hospital did not have a discharge-planning department, the item "I understand when I should consult the discharge planning department" was changed to "I understand when to consult a social worker and other staff nurses". Furthermore, in the pre-intervention questionnaires, staff nurses provided information about their age, gender, job title, years of nursing experience, and the type of institution where they received their training.

\subsubsection{I dentification of high-risk patients by staff nurses}

Before and after the intervention, the staff nurses in charge of the inpatients at admission filled in a questionnaire to identify high-risk patients. This questionnaire asked them to judge discharge planning needs using three choices: "Discharge planning is certainly required," "The necessity of discharge planning is predicted but will be judged according to the patient's condition," and "The necessity of discharge planning is unlikely" ${ }^{[33]}$. Before intervention, staff nurses completed the questionnaire after gathering the usual patient information without the STDP; post-intervention, they filled in the questionnaire after completing the STDP but were not informed about the researcher's STDP score. The number of times that ward nurses completed the tool depended on the number of nurses in charge of the patient at the time of admission during the intervention period.

A researcher carried out semi-structured interviews with patients and their families using the STDP before and after the intervention, independent of the staff nurses. The researcher also gathered information about the use of services and walking apparatus during the interview. Information about gender, diagnosis, and length of hospital stay was obtained from medical records. A correspondence list was made to collate patient designations (high-risk or not) according to the STDP completed by the researcher, and the questionnaire filled in by the staff nurse.

\subsection{Methods of analysis}

Paired $t$-tests were used to compare staff nurses' practical ability in discharge planning before and after the intervention. To compare basic characteristics of inpatients before and after the intervention, Fisher's exact test and chi-square tests were used. The significance level was set at $p<.05$ for all analyses (two-sided). SPSS 19.0 was used for analyses.

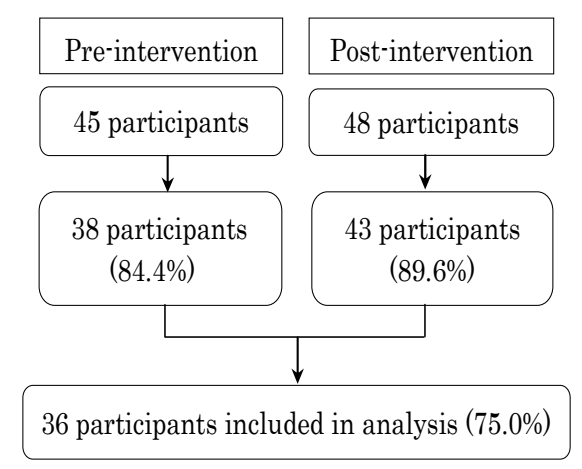

Figure 2. Flowchart of questionnaires completed by staff nurses

Note. Data were included in the analysis only if the nurse completed both questionnaires.

\subsection{Ethical considerations}

It was necessary to compare data on staff nurses before and after the intervention while maintaining the participants' anonymity. Therefore, nurses were asked to mark their hospital identification number on each questionnaire, seal it in an 
envelope without a signature, and put it in the collection bag placed in each ward. The submission of a questionnaire was considered as implied consent for participation in the study.

The purpose of the study and the format of the intervention were explained orally to patients and their families at the time of hospital admission. A document about the study was provided and written consent was obtained. The study was approved by the Ethical Committee of the Graduate School of Medicine, the University of Tokyo, and Research Hospital, The Institute of Medical Science, the University of Tokyo.

\section{Results}

\subsection{Staff nurses' self-evaluation of practical ability in discharge planning}

Questionnaires were collected from 38 staff nurses (84.4\%) before the intervention and 43 staff nurses (89.6\%) after the intervention. In total, the questionnaires of 36 staff nurses (75.0\%) were collated and included in the analysis (see Figure 2).

Table 1. Characteristics of the Staff Nurses $(n=36)$

\begin{tabular}{lll}
\hline Staff nurses & $\mathbf{n}$ & $\%$ \\
\hline Age (years) & 12 & 33.3 \\
$20-29$ & 21 & 58.3 \\
$30-39$ & 2 & 5.6 \\
$40-49$ & 1 & 2.8 \\
50 or more & & \\
Gender & 6 & 16.7 \\
$\quad$ Male & 30 & 83.3 \\
Female & & \\
Job title & 6 & 16.7 \\
$\quad$ Administrative (chief/senior vice-chief) & 30 & 83.3 \\
$\quad$ No title & & \\
Nursing experience & 7 & 19.4 \\
Less than 4 & 15 & 41.7 \\
$4-9$ & 14 & 38.9 \\
10 or more & & \\
Type of training & 10 & 27.8 \\
Four-year university/college & 8 & 22.2 \\
Three-year college (junior college) & 17 & 47.2 \\
Nursing vocational school & 1 & 2.8 \\
Other & & \\
\hline
\end{tabular}

Most staff nurses were 30-39 years old (58.3\%), and 80.6\% had at least four years of nursing experience. As for training, the majority (47.2\%) had graduated from nursing vocational schools (see Table 1).

Due to conflicting conference and work schedules, some nurses were unable to attend the conferences. However, all nurses used the screening tool. 
Table 2. Impact of the intervention on staff nurses' practical ability in discharge planning

\begin{tabular}{|c|c|c|c|c|c|c|c|c|c|c|}
\hline \multirow[b]{3}{*}{ DCP-PEM $^{\dagger}$} & \multirow[b]{3}{*}{$n$} & \multicolumn{4}{|c|}{ All staff nurses $(n=36)$} & \multicolumn{5}{|c|}{ Staff nurses participating in the conference $(n=27)$} \\
\hline & & $\begin{array}{l}\text { Pre- } \\
\text { intervention }\end{array}$ & $\begin{array}{l}\text { Post- } \\
\text { intervention }\end{array}$ & & $\begin{array}{l}\text { Difference } \\
\text { within } \\
\text { subject }\end{array}$ & & $\begin{array}{l}\text { Pre- } \\
\text { intervention }\end{array}$ & $\begin{array}{l}\text { Post- } \\
\text { intervention }\end{array}$ & & $\begin{array}{l}\text { Difference } \\
\text { within } \\
\text { subject }\end{array}$ \\
\hline & & Mean (SD) & Mean (SD) & $p^{\ddagger}$ & $\operatorname{Mean}(S D)$ & $n$ & Mean (SD) & Mean (SD) & $p^{\ddagger}$ & $\operatorname{Mean}(S D)$ \\
\hline Total & 33 & $79.4(17.7)$ & $86.3(12.5)$ & 0.015 & $6.5(14.4)$ & 24 & $81.0(16.4)$ & $88.5(12.1)$ & 0.017 & $7.2(13.8)$ \\
\hline Screening & 36 & $9.1(3.2)$ & $10.6(2.7)$ & 0.001 & $1.6(2.6)$ & 27 & $9.6(2.4)$ & $10.8(1.2)$ & 0.013 & $1.1(2.2)$ \\
\hline Assessment & 35 & $20.2(5.0)$ & $21.2(4.5)$ & 0.147 & $1.0(3.7)$ & 26 & $20.3(3.7)$ & $21.9(2.8)$ & 0.046 & $1.6(3.8)$ \\
\hline Planning & 36 & $15.5(4.4)$ & $16.2(4.1)$ & 0.274 & $0.7(3.6)$ & 27 & $15.9(3.4)$ & $16.8(3.2)$ & 0.161 & $1.0(3.4)$ \\
\hline $\begin{array}{l}\text { Implementa- } \\
\text { tion }\end{array}$ & 35 & $26.5(7.8)$ & $28.1(6.8)$ & 0.115 & $1.5(5.7)$ & 26 & $27.1(6.0)$ & $28.7(5.2)$ & 0.170 & $1.6(5.7)$ \\
\hline Monitoring & 35 & $8.8(3.0)$ & $9.9(2.5)$ & 0.014 & $1.1(2.5)$ & 26 & $8.9(2.6)$ & $10.2(1.9)$ & 0.029 & $1.2(2.7)$ \\
\hline
\end{tabular}

†DCP-PEM: Discharge Planning-Process Evaluation Measurement. SD: Standard Deviation.

${ }^{\ddagger}$ Paired $t$-test. Does not include missing values.

Table 2 shows the comparison of self-assessment of staff nurses' practical ability in discharge planning before and after the intervention. DCP-PEM scores improved significantly for the screening $(p<.001)$ and monitoring $(p=.014)$ subscales and for the sum total $(p=.015)$ after intervention. Staff nurses who participated in the conference (27 out of 36 nurses) showed improvements in the same areas as well as on the assessment subscale $(p=.046)$ of the DCP-PEM. The within-subject difference for items that were statistically significant had high mean values and small standard deviations.

\subsection{I dentification of high-risk patients by staff nurses}

Sixty-eight inpatients satisfied the inclusion criteria for participation in the survey (pre-intervention period, 38 inpatients; post-intervention period, 30 inpatients). Thirty-four patients were excluded because the physician or ward chief determined that it would be difficult to obtain their cooperation on account of their mental health concerns and treatment content (see Figure 3). Table 3 shows that characteristics of the target patients before and after the intervention were not significantly different.

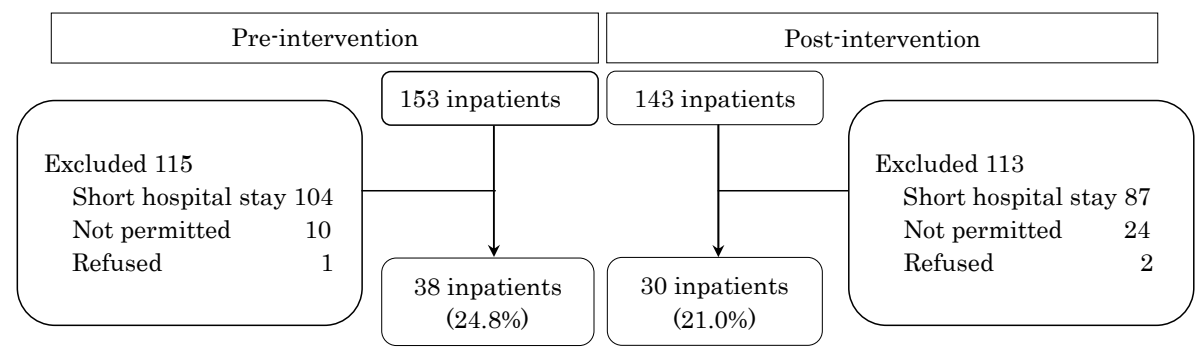

Figure 3. Flowchart of patients who meet the participation conditions of the survey

Table 4 shows the comparison of the results of the STDP completed by the researcher, and judgments by staff nurses before and after the intervention. During the pre-intervention period, 11 patients received scores of 10 or more points on the STDP completed by the researcher. Of these 11 patients, staff nurses identified 4 patients $(36.4 \%)$ as high-risk for discharge. In the post-intervention period, 13 patients received scores of 10 or more points on the STDP completed by the researcher, and staff nurses identified 8 patients $(61.5 \%)$ as high-risk for discharge. There were no significant differences (risk ratio of cure $=1.69 ; 95 \%$ confidence interval, $0.67-4.29$ ), but the percentage of patients whom staff nurses had judged to be high risk increased, as had been expected. 
Table 3. Characteristics of target patients during the pre-intervention and post-intervention period

\begin{tabular}{|c|c|c|c|c|c|}
\hline \multirow{2}{*}{ Patients } & \multicolumn{2}{|c|}{ Pre-intervention } & \multicolumn{2}{|c|}{ Post-intervention } & \multirow{2}{*}{$p$} \\
\hline & $n$ & $\%$ & $n$ & $\%$ & \\
\hline \multicolumn{6}{|l|}{ Age (years) } \\
\hline Less than 65 & 24 & 63.2 & 13 & 43.3 & $0.25^{\dagger}$ \\
\hline $65-74$ & 7 & 18.4 & 7 & 23.3 & \\
\hline 75 or more & 7 & 18.4 & 10 & 33.3 & \\
\hline \multicolumn{6}{|l|}{ Gender } \\
\hline Male & 21 & 55.3 & 14 & 46.7 & $0.48^{*}$ \\
\hline Female & 17 & 44.7 & 16 & 53.3 & \\
\hline \multicolumn{6}{|l|}{ Diagnosis $\left(\mathrm{ICD}^{\S}\right)$} \\
\hline Neoplasms & 8 & 21.1 & 5 & 16.7 & $0.82^{\dagger}$ \\
\hline Musculoskeletal system diseases & 7 & 18.4 & 5 & 16.7 & \\
\hline Nutritional diseases & 5 & 13.2 & 5 & 16.7 & \\
\hline Certain infectious diseases & 5 & 13.2 & 1 & 3.3 & \\
\hline Digestive system diseases & 4 & 10.5 & 2 & 6.7 & \\
\hline Skin and subcutaneous tissue diseases & 3 & 7.9 & 3 & 10.0 & \\
\hline Blood-forming organs diseases & 2 & 5.3 & 2 & 6.7 & \\
\hline Respiratory system diseases & 1 & 2.6 & 3 & 10.0 & \\
\hline Genitourinary system diseases & 1 & 2.6 & 1 & 3.3 & \\
\hline Symptoms not classified & 1 & 2.6 & 3 & 10.0 & \\
\hline Injury and poisoning & 1 & 2.6 & 0 & 0.0 & \\
\hline \multicolumn{6}{|l|}{ Hospital stay (days) } \\
\hline 14 or less & 23 & 60.5 & 18 & 60.0 & $0.33^{\dagger}$ \\
\hline $15-29$ & 8 & 21.1 & 3 & 10.0 & \\
\hline 30 or more & 7 & 18.4 & 9 & 30.0 & \\
\hline \multicolumn{6}{|l|}{ Living arrangement } \\
\hline With someone & 31 & 81.6 & 21 & 70.0 & $0.39^{*}$ \\
\hline Alone & 7 & 18.4 & 9 & 30.0 & \\
\hline \multicolumn{6}{|l|}{ ADL $^{\text {ๆ needing assistance }}$} \\
\hline Transferring & 2 & 5.3 & 3 & 10.0 & $0.65^{\dagger}$ \\
\hline Toileting & 1 & 2.6 & 2 & 6.7 & $0.58^{\dagger}$ \\
\hline \multicolumn{6}{|l|}{ Walking apparatus } \\
\hline Required & 8 & 21.1 & 9 & 30.0 & $0.40^{*}$ \\
\hline \multicolumn{6}{|l|}{ Cognitive function } \\
\hline Impairment & 1 & 2.6 & 3 & 10.0 & $0.31^{\dagger}$ \\
\hline \multicolumn{6}{|l|}{ Family care system } \\
\hline Problems & 25 & 65.8 & 20 & 66.7 & $0.94^{\ddagger}$ \\
\hline \multicolumn{6}{|l|}{ Long-term care insurance } \\
\hline Receiving & 5 & 13.2 & 5 & 16.7 & $0.69^{*}$ \\
\hline \multicolumn{6}{|l|}{ Services } \\
\hline Using & 3 & 7.9 & 4 & 13.3 & $0.69^{\dagger}$ \\
\hline \multicolumn{6}{|l|}{ Medical measures(Except taking medicine) } \\
\hline Necessary & 4 & 10.5 & 6 & 20.0 & $0.32^{\dagger}$ \\
\hline
\end{tabular}

${ }^{\dagger}$ Fisher's exact test. ${ }^{*} \chi^{2}$ test. ${ }^{\S} \mathrm{ICD}$ : International Classification of Diseases.

"ADL: Activities of Daily Living. 
Table 4. Staff nurses' judgments of high-risk patients

\begin{tabular}{|c|c|c|c|c|c|}
\hline \multirow{3}{*}{$\begin{array}{l}\text { Researcher's STDP }^{\dagger} \text { score } \\
\text { Nurse's judgment }\end{array}$} & \multirow{2}{*}{\multicolumn{2}{|c|}{$\begin{array}{l}\text { Pre-intervention } \\
10 \text { or more points on } \text { STDP }^{\dagger} \\
(n=11)\end{array}$}} & \multirow{2}{*}{\multicolumn{2}{|c|}{$\begin{array}{l}\text { Post-intervention } \\
10 \text { or more points on } \text { STDP }^{\dagger} \\
(n=13)\end{array}$}} & \multirow{3}{*}{$\boldsymbol{p}^{\ddagger}$} \\
\hline & & & & & \\
\hline & $n$ & $\%$ & $n$ & $\%$ & \\
\hline High-risk & 4 & 36.4 & 8 & 61.5 & 0.20 \\
\hline Non-high-risk & 7 & 63.6 & 5 & 38.5 & \\
\hline
\end{tabular}

$\dagger$ †TDP: Screening Tool for Discharge Planning.

$\ddagger \chi^{2}$ test. Does not include missing values.

Table 5. Characteristics of high-risk patients identified by staff nurses

\begin{tabular}{|c|c|c|c|c|c|}
\hline \multicolumn{3}{|c|}{ Pre-intervention $(N=11)$} & \multicolumn{3}{|c|}{ Post-intervention $(N=13)$} \\
\hline & $\begin{array}{l}\text { High-risk } \\
(n=4)\end{array}$ & $\begin{array}{l}\text { Not-high-risk } \\
(n=5)\end{array}$ & & $\begin{array}{l}\text { High-risk } \\
(n=8)\end{array}$ & $\begin{array}{l}\text { Not-high-risk } \\
(n=5)\end{array}$ \\
\hline$N$ & $\%$ & $\%$ & $N$ & $\%$ & $\%$ \\
\hline
\end{tabular}

\section{Age (years)}

75 or more

$\begin{array}{lllll}6 & 2 & 33.3 & 4 & 66.7\end{array}$

66.7

$\begin{array}{lll}8 & 6 & 75.0\end{array}$

$2 \quad 25.0$

0.28

\section{Living arrangement}

Alone

$\begin{array}{llll}3 & 1 & 33.3 & 2\end{array}$

66.7

$\begin{array}{lll}3 & 2 & 66.7\end{array}$

$1 \quad 33.3$

0.41

Family care system

Problems

$\begin{array}{lllll}8 & 3 & 37.5 & 5 & 62.5\end{array}$

62.5

$\begin{array}{lll}10 & 6 & 60.0\end{array}$

$4 \quad 40.0$

0.64

Activities of daily living ${ }^{\ddagger}$

$\begin{array}{llllllllllll}\text { Assistance needed } & 1 & 1 & 100.0 & 0 & 0.0 & 2 & 2 & 100.0 & 0 & 0.0 & 1.00\end{array}$

Walking apparatus

Required

233

$4 \quad 66.7$

\section{Cognitive function}

$$
\text { Impairment }
$$

$\begin{array}{lll}1 & 0 & 0.0\end{array}$

$1 \quad 100.0$

$\begin{array}{lll}3 & 3 & 100.0\end{array}$

0

\section{Long-term care}

insurance

Not receiving

Services

Using

$\begin{array}{lll}6 & 1 & 16.7\end{array}$

$6.7-5$

83.3

$\begin{array}{lll}5 & 3 & 60.0\end{array}$

$2 \quad 40.0$

$\begin{array}{lll}8 & 5 & 62.5\end{array}$

3

37.5

0.14

Medical measures $^{\S}$

Necessary

$\begin{array}{lllll}1 & 1 & 100.0 & 0 & 0.0\end{array}$

0

${ }^{\dagger}$ Fisher's exact test. ${ }^{\ddagger}$ Transferring and toileting. ${ }^{\S}$ Except taking medicine.

Table 5 shows the characteristics of high-risk patients identified by staff nurses before and after the intervention. The staff nurses judged as high-risk, all patients with medical treatments and needing assistance in the daily activities of transferring and toileting. There was an increase in ratios of patients with cognitive functional impairment, problems with family care, use of walking apparatus and services, and not receiving LTCI who were judged by staff nurses to be high-risk after, than before the intervention, but the differences were not significant. 


\section{Discussion}

In this study, we adopted the STDP and discharge conferences as part of the daily nursing practices in a hospital without a discharge-planning department, and clarified the impacts of the intervention on staff nurses' practical ability in discharge planning and on the identification of high-risk patients by staff nurses.

\subsection{I mpacts of the intervention on participants}

\subsubsection{Staff nurses' self-evaluation of practical ability in discharge planning}

After the intervention, participant scores on the screening and monitoring subscales and the sum total score of the DCP-PEM increased significantly.

The improvement in screening ability was consistent with a previous study that introduced an educational program ${ }^{[27]}$. In the present study, conferences were held to discuss high-risk patients who were deemed as requiring discharge planning. As expected, after introducing conferences, ward nurses were better able to understand and identify the characteristics of high-risk patients requiring discharge planning, particularly when using the STDP at the patient's admission. Despite the small sample size, it appeared that the nurses had a better understanding because of the conferences and tools.

The monitoring subscale evaluates consciousness about discharge planning. A previous study found an improvement in understanding the importance of gathering information, cooperating with other professionals, and preparing for discharge, as a result of an intervention that included a screening tool ${ }^{[21]}$. In the present study, staff nurses' awareness about discharge planning increased as they learned about the process of discharge management, cooperated with other professionals at conferences, and gathered information using the STDP. Thus, the self-evaluation of staff nurses' practical ability for discharge planning improved significantly.

In the analysis that included only the staff nurses who participated in conferences, the self-evaluation of assessment ability increased significantly after the intervention. Participation in conferences may have improved self-evaluations of practical ability, particularly for assessment, especially since nurses received information and advice from other staff nurses resulting in multifaceted, elaborate assessments.

The self-evaluations regarding care planning and implementation ability did not show significant improvements. The conference style used in this study emphasized general guidance and support in the assessment process of discharge planning. This lack of concrete discussion about timing and methods of arrangement and monitoring, and the lack of enforcement of the discharge plan may explain why self-ratings for care planning and implementation did not improve significantly.

\subsubsection{I dentification of high-risk patients by staff nurses}

Although the ratio of patients identified as high-risk by staff nurses increased after the intervention, the difference was not statistically significant. Staff nurses identified patients with cognitive functional impairment, problems with family care, and those using walking apparatus as high-risk at a lower rate before the intervention, than after. Previous studies, including a study investigating the need for continuing care, and problems 6-10 days after discharge of 260 adults ${ }^{[34]}$, and a study analyzing 99 patients with poor post-discharge outcomes without home care referrals ${ }^{[35]}$, pointed out that staff nurses tend to overestimate the self-care capabilities and favorably misjudge the home environment of the patients. Our study initially indicated similar findings, but after the intervention, staff nurses were better able to identify high-risk patients. Use of the STDP made it easier for them to evaluate patients' ADL capabilities and the family care system accurately. The STDP does not contain items about the use of walking apparatus and risks of falling; however, in conferences, a researcher advised nurses about the benefits provided by LTCI for walking apparatus and the need for preventive discharge planning. Staff nurses gathered this information along with information about necessary assistance and ADL, and patients who were classified into these categories were more likely to be identified as high-risk. 
The ratios of patients without LTCI and using services who were identified as high-risk increased after the intervention. Although these differences were not significant, it is worth noting that staff nurses identified all patients using services as high-risk for discharge after the intervention. The understanding of services is low among staff nurses ${ }^{[10]}$, and it has been reported that they have difficulty judging patient needs in this area ${ }^{[36]}$. However, staff nurses gathered information about the use of services along with the LTCI assessment through one item of the STDP. Furthermore, the conference may have helped nurses recognize the management of services by the physician because the conference involved sharing information about the purposes of consulting external institutions, and identifying which patients would be likely to receive LTCI.

On the other hand, staff nurses identified all patients needing assistance with transferring as high-risk, before and after the intervention. Patients with reduced ADL abilities generally require substantial assistance, thus classifying such patients as high-risk was easy for staff nurses. They judged all patients needing some sort of ongoing medical treatment to be high-risk both pre- and post-intervention. In a previous study, it was reported that predicting the need for continued medical measures after discharge is difficult for staff nurses ${ }^{[37]}$. In the current study, the prediction of patients needing education or additional support was easy for nurses because all patients had been receiving some form of medical treatment before admission. For patients requiring new or additional medical measures after discharge, the intervention effects on the judgments of staff nurses was not clear in the current study.

\subsection{Limitations and importance of the Study}

A limitation of this study was the lack of a control group; because we carried out the intervention with all staff nurses, we were not able to consider other influences, such as increased maturity over time. In addition, frequency of conferences and the use of the STDP differed in each ward, and one researcher provided non-standardized advice during the conferences; these differences - in the frequency of interventions and varied instructions provided to staff nurses during the conference - that were not controlled in the study may have influenced the results.

Generalization of the results of this study may be difficult because only one hospital was included. Furthermore, to improve the staff nurses' identification of high-risk patients and need for discharge planning, a sufficiently long intervention period was necessary. Moreover, the present study had a small sample size. The limited number of nurses, a characteristic of a middle-scale hospital, the small number of patients due to a short intervention period, and the large number of exclusions because of short-term hospital admissions, ultimately proved to be insufficient. Future studies must utilize research designs that enable comparison with a control group. Studies with longer intervention durations and larger samples are needed to confirm the present findings.

In this study, conference content could be unified for consistency, but the conference structure was found to vary. That is, the conference content, including sharing patient information, assessment of home care, its direction, and support were similar. However, the frequency, duration, and conference procedures differed considerably between wards. It was likely that information sharing and discussions at the conference had an effect on staff nurses' evaluations. However, the conference structure has not yet been validated. It is also necessary to standardize the conference structure.

However, this study is the first to evaluate the effects of the adoption of the STDP and discharge-related conferences in a hospital without a discharge-planning department. This study demonstrates the potential benefits of the STDP and discharge conferences, particularly for identification of high-risk patients by staff nurses, and self-evaluations of their discharge-planning abilities in a mid-size hospital where establishing a discharge-planning department would be difficult. In medium-sized hospitals with no discharge planning department, thus without a nurse who specializes in discharge planning, incorporating interventions such as conferences or screening tools into daily nursing practice systems may improve staff nurses' ability to conduct discharge planning. Further, this study is significant since it can be expected that improvement of practical ability will lead to the implementation of discharge planning by staff nurses. Further studies employing a research design that utilizes a control group are required. Additionally, studies that unify the conference 
structure, extends the intervention period, and uses a larger sample size could verify our findings and contribute further to research.

\section{Conclusion}

We adopted the STDP and discharge conference as part of daily nursing practices to enhance staff nurses' practical ability in discharge planning in a hospital without a discharge-planning department and investigated their impacts. These interventions were accompanied by an improvement in the DCP-PEM subscales for screening, assessment, and monitoring, and the DCP-PEM sum total score. In addition, the ratios of high-risk patients identified by staff nurses increased after the intervention. In medium-sized hospitals, specialists' placements for discharge planning are difficult. Thus, staff nurses could identify patients in need of discharge planning by incorporating conferences and screening tools as part of daily nursing practices. Future research examining methods of continued use of tools and conferences in daily nursing practices is required.

\section{Acknowledgements}

We wish to express our gratitude to the participants of this study. This study was funded by the Ministry of Health Labour and Welfare, Japan through the Health and Labour Science Research Grant, 2011.

\section{References}

[1] Nagata S. Current situation and problems inherent to discharge planning in practice. Gan To Kagaku Ryoho. 2004; 31: 159-61(in Japanese).

[2] Japan Ministry of Health, Welfare, and Labor. Shinryou houshuu kaitei no gaiyou. 2012[cited 2014 Jun 25]. Available from: http://www.mhlw.go.jp/bunya/iryouhoken/iryouhoken15/d1/h24_01-03.pdf

[3] Japan Ministry of Health, Welfare, and Labor. Taiin chousei: iryou kaigo renkei. 2008[cited 2014 Jun 25]. Available from: http://www.mhlw.go.jp/stf/shingi/2r98520000011ga6-att/2r98520000011gkm.pdf

[4] Nagata S, Tomura H, Murashima S. Expansion of discharge planning system in Japan: Comparison of results of a nationwide survey between 2001 and 2010. BMC Health Services Research [Internet]. 2012[cited 2014 Jun 25]. Available from: http://www.biomedcentral.com/1472-6963/12/237

[5] Matsunaga A, Nagata S, Murashima S. Implementation and perception of discharge planning by ward nurses at two special function hospitals: Comparison between hospitals with and without a discharge planning department. Journal of the Japanese Society on Hospital Administration. 2004; 41(3): 21-30(in Japanese).

[6] Nagata S, Tabata M, Oshima H, Murashima S, Sumi N, Haruna M. Current status of discharge planning activities and system: National survey of discharge planning in Japan. Japan Journal of Nursing Science. 2004; 1: 87-97. http://dx.doi.org/10.1111/j.1742-7924.2004.00015.x

[7] Japan Visiting Nursing Foundation. Taiinchouseikangoshi nikansuru jittaichousa. 2011[cited 2014 Jun 25]. Available from: www.nurse.or.jp/home/zaitaku/hokokusho/pdf/gittaichosa.pdf

[8] Clare J, Hofmeyer A. Discharge planning and continuity of care for aged people: Indicators of satisfaction and implications for practice. The Australian Journal of Advanced Nursing. 1998; 16: 7-13. PMid:9807277

[9] Bowles KH, Foust JB, Naylor MD. Hospital discharge referral decision making: A multidisciplinary perspective. Applied Nursing Research. 2003; 16: 134-43. http://dx.doi.org/10.1016/S0897-1897(03)00048-X

[10] Tome M, Ueno N, Kimura M. Knowledge of hospital nurses about services. Journal of Japanese Society of Nursing Research. 1999; 22(5): 9-21(in Japanese).

[11] Kalisch BJ. Missed nursing care: A qualitative study. Journal of Nursing Care Quality. 2006; 21(4): 306-13. PMid:16985399 http://dx.doi.org/10.1097/00001786-200610000-00006

[12] Department of Health, Health \& Social Care Joint Unit and Change Agents Team. Discharge from hospital: Pathway, process and practice. 2003[cited 2014 Jun 25]. Available from:

http://www.dh.gov.uk/prod_consum_dh/groups/dh_digitalassets/@dh/@en/documents/digitalasset/dh_4116525.pdf

[13] Morris J, Winfield L, Young K. Registered nurses' perceptions of the discharge planning process for adult patients in an acute hospital. Journal of Nursing Education and Practice. 2012; 2(1): 28-38. http://dx.doi.org/10.5430/jnep.v2n1p28 
[14] Nosbusch JM, Weiss ME, Bobay KL. An integrated review of the literature on challenges confronting the acute care staff nurse in discharge planning. Journal of Clinical Nursing. 2011; 20: 754-74. PMid:20955476

http://dx.doi.org/10.1111/j.1365-2702.2010.03257.x

[15] Slade A, Fear J, Tennant A. Identifying patients at risk of nursing home admission: The Leeds Elderly Assessment Dependency Screening tool (LEADS). BMC Health Services Research[Internet]. 2006; 6(31) [cited 2014 Jun 25]. Available from http://www.ncbi.nlm.nih.gov/pmc/articles/PMC1513555/pdf/1472-6963-6-31.pdf

[16] Sumi N, Murashima S. Development of a screening tool to predict needs of discharge planning for elderly patients upon hospital admission (part 1). Journal of the Japanese Society on Hospital Administration. 2005a; 42(3): 277-88 (in Japanese).

[17] Sumi N, Murashima S. Development of a screening tool to predict needs of discharge planning for elderly patients upon hospital admission (part 2): Validation of screening tool in a university hospital. Journal of the Japanese Society on Hospital Administration. 2005b; 42(4): 479-91 (in Japanese).

[18] Bull MJ. A discharge planning questionnaire for clinical practice. Applied Nursing Research. 1999; 7: $193-207$. http://dx.doi.org/10.1016/0897-1897(94)90027-2

[19] Mistiaen P, Duijnhouwer E, Prins-Hoekstra A, Ros W, Blaylock A. Predictive validity of the BRASS index in screening patients with post-discharge problems. Journal of Advanced Nursing. 1999; 30(5): 1050-6. PMid:10564403 http://dx.doi.org/10.1046/j.1365-2648.1999.01203.x

[20] Sumi N, Okuhara Y, Adachi T, Asano H, Sato Y. Validity of a revised screening tool for identifying patients in need of discharge planning at a university hospital. Journal of Comprehensive Nursing Research. 2007; 10(3): 53-64(in Japanese).

[21] Sakai S, Shino S, Ohori Y, Tanaka Y. Change in unit nurses' knowledge and practice before or after the intervention by using a discharge support planning tool at highly advanced medical center. Gan To Kagaku Ryoho. 2010; 37: 169-71(in Japanese). PMid:21368512

[22] Dedhia P, Kravet S, Bulger J, Hinson T, Sridharan A, Kolodner K, ... Howell E. A quality improvement intervention to facilitate the transition of older adults from three hospitals back to their homes. Journal of the American Geriatrics Society. 2009; 57(9): 1540-6. PMid:19694865 http://dx.doi.org/10.1111/j.1532-5415.2009.02430.x

[23] Yamada T, Kanzaki S, Yosimura Y, Suzuki M, Omori N. Efficacy of discharge arrangements by utilizing a risk-screening checklist on admission. The Journal of Japan Society for Health Care Management. 2007; 7(4): 530-5(in Japanese).

[24] Chapman LJ, Murphy DJ, Kiernan NE, Goldenhar L. An improved model for professional conferences and workshops. American Journal of Industrial Medicine. 1996; 29: 342-5. http://dx.doi.org/10.1002/(SICI)1097-0274(199604)29:4<342::AID-AJIM12>3.0.CO;2-1

[25] Arroyo M, Rocandio AM, Ansotegui L, Pascual E, Martinez de la Pera C. Cooperative learning strategies to teach nutrition to geriatric nursing staff. Archivos Latinoamericanos de Nutricion. 2008; 58(1): 27-32. PMid:18589569

[26] Slavin RE. Cooperative learning: Theory, research, and practice. 2nd ed. Boston: Allyn and Bacon;1995. 45-6 p.

[27] Suzuki S, Nagata S, Zerwekh J, et al. Effects of a multi-method discharge planning educational program for medical staff nurses. Japan Journal of Nursing Science. 2012; 9(2): 201-15. PMid:23181889 http://dx.doi.org/10.1111/j.1742-7924.2011.00203.x

[28] Balaban RB, Weissman JS, Samuel PA, Woolhandler S. Redefining and redesigning hospital discharge to enhance patient care: A randomized controlled study. Journal of General Internal Medicine. 2008; 23(8): 1228-33. PMid:18452048 http://dx.doi.org/10.1007/s11606-008-0618-9

[29] Naylor M, Brooten D, Jones R, Lavizzo-Mourey R, Mezey M, Pauly M. Comprehensive discharge planning for the hospitalized elderly: A randomized clinical trial. Annals of Internal Medicine. 1994; 120(12): 999-1006. PMid:8185149 http://dx.doi.org/10.7326/0003-4819-120-12-199406150-00005

[30] Shirasawa M. Creation of care plan. Japanese Journal of Geriatric Psychiatry. 2003; 14(9): 1081-9(in Japanese).

[31] Rorden JW, Taft E. Discharge planning guide for nurses. Philadelphia: W.B. Saunders Company;1990: $42-4$ p.

[32] Chiba Y. Development and validation of the discharge planning-process evaluation measurement. Journal of Japan Academy of Nursing Science. 2005; 25(4): 39-51(in Japanese). http://dx.doi.org/10.5630/jans1981.25.4_39

[33] Utsunomiya H. Navigation of practice in discharge planning. Tokyo:Igaku-shoin;2011: 30-7 p (in Japanese).

[34] Holland DE, Knafl GJ, Bowles KH. Targeting hospitalized patients for early discharge planning intervention. Journal of Clinical Nursing. 2012: 1-8.

[35] Bowles KH, Naylor MD, Foust JB. Patient characteristics at hospital discharge and a comparison of home care referral decisions. Journal of the American Geriatrics Society. 2002; 50(2): 336-42. PMid:12028217 http://dx.doi.org/10.1046/j.1532-5415.2002.50067.x

[36] Maruoka N, Horanai Y, Kawashima K, et al. The actual situation and issues discharge planning activities of ward nurses - Investigation using discharge planning quality indicators. Ishikawa Journal of Nursing. 2011; 8: 29-38(in Japanese).

[37] Hondo K. The factor and measure which obstruct smooth discharge planning. Kangotenbo. 2000; 25: 17-21(in Japanese). 